\title{
VALIDAÇÃO DE UM DESENHO EXPERIMENTAL PARA TESTES SENSORIAIS COMPARATIVOS COM MUITAS AMOSTRAS
}

\author{
Claudete C.J. CHIAPPINI", Aline B. BARBOSA, Samira C. FIGUEIREDO , Selma G.F. LEITE
}

\section{RESUMO}

Nos estudos em análise sensorial a limitação fisiológica dos órgãos dos sentidos dos provadores é um dos fatores a se levar em consideração no planejamento dos testes. O objetivo deste estudo foi validar um desenho experimental para testes comparativos com muitas amostras. Cultivos de leveduras produtoras de aroma frutal foram escolhidas por provadores não treinados e cultivados em caldo YEPD e caldo Melaço. Testes sensoriais de ordenação e de escala foram realizados com 8 linhagens selecionadas e 3 linhagens referência para seleção da melhor linhagem produtora de aroma frutal, em cada meio de cultura, por uma equipe de provadores treinada. A aplicabilidade e a habilidade discriminatória do desenho experimental foi validada por meio de análise estatística. No tratamento estatístico foi utilizado o teste de Friedman para os testes de ordenação e a análise de variância e o teste de Tukey para os testes de escala. Todas as amostras foram comparadas e foram encontradas diferenças significativas ao nível de $5 \%$ entre elas. As amostras puderam ser comparadas sem fadiga da equipe de provadores.

Palavras-chave: análise sensorial; testes comparativos; desenho experimental; culturas de leveduras; aroma frutal.

\section{SUMMARY}

VALIDATION OF AN EXPERIMENTAL DESIGN FOR SENSORY COMPARATIVE TESTS WITH MANY SAMPLES. In sensory analysis studies the physiological limitation of the panelists sense organs is one of the concerns during tests planning. The aim of this study was to validate an experimental design for comparative tests with many samples. Yeast cultures producing fruit aroma were selected by non-trained testers and cultured in YEPD and molasses-based broths. Ranking and hedonic scale sensory tests were carried out with 8 selected strains and 3 other reference strains for selection of the best producer strain in each medium by a trained sensory panel. The following statistical treatments were used: Friedman's test for ranking tests and variant analysis and Tukey's test for scale tests to determine applicability and discriminatory ability of the experimental design. All the samples were compared and significant differences were found between them. The samples could be compared without panelists fatigue.

Keywords: sensory analysis; comparative tests; experimental design; yeast cultures; fruit aroma.

\section{1 - INTRODUÇÃO}

Por definição, análise sensorial implica no uso dos sentidos e é realizada por pessoas treinadas selecionadas com base na consistência e na habilidade de discriminar. Devido aos instrumentos que utiliza para a avaliação sensorial, é possivel entender as limitações fisiológicas da equipe de provadores e a sua impossibilidade de comparar muitas amostras numa mesma sessão de análise sensorial. Equipes de provadores freqüentemente podem testar somente um número limitado de amostras por sessão [2].

MEILGAARD, CIVILLE \& CARR [9] citam como exemplo de metodologia para a análise comparativa de um grande número de amostras, um desenho experimental, onde as amostras são organizadas por combinação mate-

Recebido para publicação em 28/04/2004. Aceito para publicação em 25/07/2005(001331).

Programa de Pós-Graduação em Ciência de Alimentos, Departamento de Bioquímica, IQ, Universidade Federal do Rio de Janeiro(UFRJ).E-mail: chiappini2@yahoo.com

Departamento de Nutrição e Dietética, CMN, Universidade Federal Fluminense (UFF), Niterói-RJ, Brasil.

Departamento de Engenharia Bioquímica, EQ, CT, Universidade Federal do Rio de Janeiro (UFRJ). Endereço:, Bloco E, Ilha do Fundão. CEP: 21949-900, Rio de Janeiro-RJ, Brasil.

A quem a correspondência deve ser enviada. mática em blocos incompletos. Estes autores descrevem um experimento onde foram formados quinze blocos com 4 amostras e, por meio de teste de escala, cada provador treinado julgou um dos blocos formados usando teste de escala. Neste desenho experimental, quanto maior o número de amostras, maior será o número de blocos formados e, como cada provador julga 1 bloco, conseqüentemente, mais provadores terão que ser treinados. Isto significa aumento de tempo e do custo para o treinamento da equipe.

O planejamento de um experimento econômico deve levar em conta a escolha de um desenho experimental eficiente, que necessite o mínimo de recursos e que resulte em boa qualidade de dados. Isto significa usar um pequeno número de provadores, despender pouco tempo para o treinamento, usar os métodos sensoriais mais simples, com o mínimo de repetições possiveis. Os dados devem ser precisos e validados com algum teste externo ao experimento [10].

A produção de aroma por microrganismos em queijo $[5,8]$, em vinho $[3,6,7,11]$ e em cerveja [12] vem sendo avaliada por técnicas de análise sensorial, entretanto, relatos sobre avaliação sensorial de aroma produzido por leveduras isoladas de frutas não foram encontrados.

O objetivo deste estudo foi validar um desenho experimental para testes comparativos com muitas amostras. Uma equipe treinada foi utilizada para comparação e seleção das melhores leveduras produtoras de aroma frutal, cultivadas em caldo YEPD e caldo Melaço. 


\section{2 - MATERIAL E MÉTODOS}

\section{1 - Amostras}

Noventa e duas linhagens de leveduras selvagens de nossa coleção de culturas e 3 linhagens de Saccharomyces cerevisiae do Centro Nacional de Pesquisa da Uva e do Vinho EMBRAPA (Bento Gonçalves, BR) foram comparadas. Todas as linhagens foram codificadas com letras.

\section{2 - Seleção das leveduras produtoras}

As linhagens de leveduras foram crescidas em meio de cultura com extrato de levedura, peptona e glicose (ágar YEPD) [1] a $25 \pm 1^{\circ} \mathrm{C}$ por 3 dias. Estas linhagens foram apresentadas a uma equipe não treinada de $6 \mathrm{mem}$ bros que abriram as placas assepticamente, cheiraram as amostras e listaram os códigos das amostras, selecionando as linhagens produtoras por meio da presença ou ausência de aroma frutal.

\section{3 - Recrutamento e treinamento da equipe de provadores}

A equipe de provadores foi criada por meio de teste de reconhecimento de aroma. Neste teste, 20 frascos Erlenmeyer com diferentes produtos odoriferos, envoltos em folha de alumínio e codificados com 3 dígitos numéricos, foram apresentados aos voluntários. Os voluntários foram instruídos a cheirar as amostras e anotar, ao lado de cada código, o odor detectado. Os provadores foram escolhidos entre aqueles que obtiveram a soma mínima de 42 pontos no teste de reconhecimento de aroma. Os voluntários selecionados foram treinados em 2 testes sensoriais, de sensibilidade (teste de estímulo constante) e de diferença (teste triangular) [9], utilizando o caldo YEPD e o caldo Melaço [4, 13] contendo quantidades crescentes de acetato de amila e caldo de cultura puro como padrão.

\section{4 - Testes comparativos}

Após a etapa de treinamento, a equipe de provadores comparou as linhagens produtoras escolhidas pela equipe não treinada e selecionou a melhor produtora de aroma frutal em cada meio de cultura. Inicialmente foi realizado um sorteio para formar 3 grupos de amostras distribuídas ao acaso e, em seguida, foi realizado o teste de ordenação para cada grupo. Para este teste, 10 células $/ \mathrm{mL}$ provenientes de um pré-inóculo foram transferidas para $20 \mathrm{~mL}$ de caldo YEPD e $20 \mathrm{~mL}$ de caldo Melaço, distribuídos em frascos Erlenmeyer de $50 \mathrm{~mL}$ que foram incubados a $25 \pm 1^{\circ} \mathrm{C}$ por 3 dias ( $\mathrm{pH} 5$ ). Os provadores organizaram as amostras de cada grupo em ordem decrescente de intensidade de aroma frutal, classificando-as em $1^{\circ}, 2^{\circ}$, $3^{\circ}$ e $4^{\circ}$ lugares (Figura 1). A escolha da amostra com aroma frutal mais forte, em cada classificação, foi realizada por meio de escala numérica estruturada crescente de 10 pontos e 5 categorias de intensidade (Figura 2) [9]. A amostra escolhida como a de maior intensidade do aro- ma fractal entre as outras do $1^{\circ}$ lugar foi eliminada do grupo experimental. As demais continuaram no teste de escala e passaram a constituir um grupo de 6 amostras junto a algumas amostras do $2^{\mathrm{o}}$ lugar da classificação. E assim por diante, grupos de 6 amostras foram sendo constituídos e sendo submetidos a um novo teste de escala, de modo que, ao final dos testes, todas as amostras foram comparadas direta ou indiretamente.

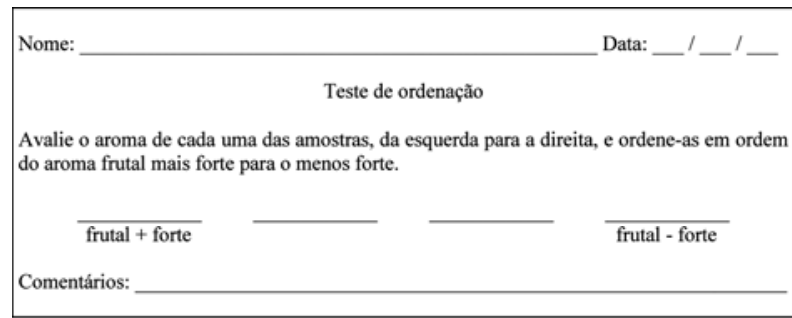

FIGURA 1 - Formulário utilizado no teste de ordenação

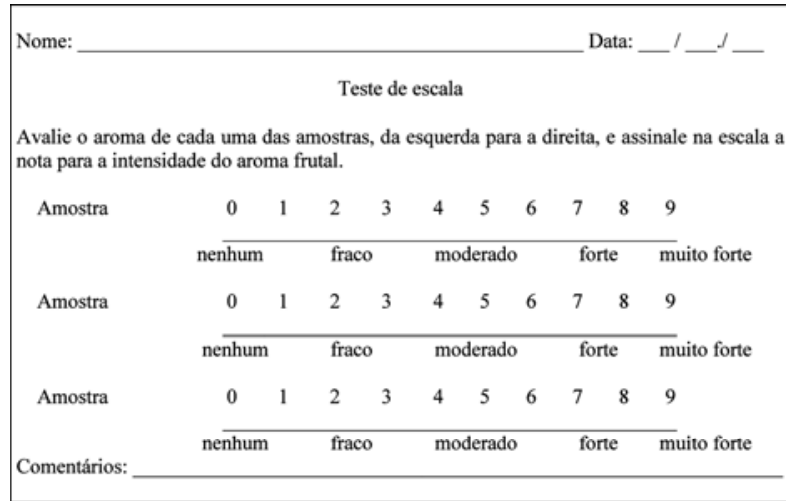

FIGURA 2 - Formulário usado no teste de escala

\section{5 - Análise estatística}

Os resultados dos testes comparativos foram analisados por testes estatísticos para validar o desenho experimental proposto. Os dados do teste de ordenação foram analisados usando o teste de Friedman e os dados do teste de escala foram analisados utilizando a análise de variância (ANOVA) e o teste de Tukey para a comparação das médias.

\section{3 - RESULTADOS E DISCUSSÃO}

Entre as 92 linhagens testadas, 11 linhagens de leveduras foram escolhidas pela equipe de provadores não treinada como produtoras de aroma frutal, de acordo com a presença ou ausência deste atributo. As linhagens escolhidas foram codificadas como A, B, C, D, E, F, G, H, I, J e K. 
Foram escolhidos 11 voluntários, entre aqueles que obtiveram a soma minima de 42 pontos no teste de reconhecimento de aroma, para fazer parte da equipe de provadores treinada.

Os 3 grupos formados por sorteio foram: $\left(1^{\circ}\right) \mathrm{D}, \mathrm{C}, \mathrm{I}$,

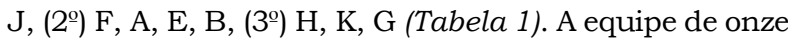
provadores ordenou as amostras de cada grupo em ordem decrescente de intensidade de aroma frutal. O resultado obtido no teste de ordenação foi a formação de novos grupos com as seguintes amostras: em $1^{\circ}$ lugar $\mathrm{C}, \mathrm{A} \mathrm{e}$ $\mathrm{H}$; em $2^{\circ}$ lugar D, F e K; em $3^{\circ}$ lugar J, B e G; e em 4º lugar I e E no caldo YEPD (Tabela 2). No caldo Melaço os novos grupos obtidos foram: em $1^{\circ}$ lugar $\mathrm{D}, \mathrm{F} \mathrm{e} \mathrm{K}$, em $2^{\circ}$ lugar $\mathrm{C}$, B e H; em 3ํo lugar J, A e G; e em 4ํo lugar I e E (Tabela 3).

TABELA 1 - Amostras distribuídas em grupos formados por sorteio

\begin{tabular}{llcll} 
teio & \multicolumn{5}{c}{ Grupos formados } \\
\hline $1^{\circ}$ grupo & $\mathrm{D}$ & $\mathrm{C}$ & $\mathrm{I}$ & $\mathrm{J}$ \\
$2^{\circ}$ grupo & $\mathrm{F}$ & $\mathrm{A}$ & $\mathrm{E}$ & $\mathrm{B}$ \\
$3^{\circ}$ grupo & $\mathrm{H}$ & $\mathrm{K}$ & $\mathrm{G}$ & \\
\hline
\end{tabular}

TABELA 2 - Classificação das amostras de acordo com os testes de ordenação em caldo YEPD

\begin{tabular}{ccccc}
\hline & $1^{\circ}$ lugar & $2^{\circ}$ lugar & $3^{\circ}$ lugar & $4^{\circ}$ lugar \\
\hline $1^{\circ}$ grupo & $\mathrm{C}$ & $\mathrm{D}$ & $\mathrm{J}$ & $\mathrm{I}$ \\
$2^{\circ}$ grupo & $\mathrm{A}$ & $\mathrm{F}$ & $\mathrm{B}$ & $\mathrm{E}$ \\
$3^{\circ}$ grupo & $\mathrm{H}$ & $\mathrm{K}$ & $\mathrm{G}$ & \\
\hline
\end{tabular}

TABELA 3 - Classificação das amostras de acordo com os testes de ordenação em caldo Melaço

\begin{tabular}{ccccc}
\hline & $1^{\circ}$ lugar & $2^{\circ}$ lugar & $3^{\circ}$ lugar & $4^{\circ}$ lugar \\
\hline $1^{\circ}$ grupo & $\mathrm{D}$ & $\mathrm{C}$ & $\mathrm{J}$ & $\mathrm{I}$ \\
$2^{\circ}$ grupo & $\mathrm{F}$ & $\mathrm{B}$ & $\mathrm{A}$ & $\mathrm{E}$ \\
$3^{\circ}$ grupo & $\mathrm{K}$ & $\mathrm{H}$ & $\mathrm{G}$ & \\
\hline
\end{tabular}

No primeiro grupo de amostras cultivadas no caldo YEPD, C - J; C - I; D - J e D - I apresentaram diferença significativa ao nivel de $5 \%$ de acordo com o teste de Friedman. No $2^{\mathrm{o}}$ grupo, as amostras A - E mostraram diferença significativa, entretanto, no $3^{\text {o }}$ grupo nenhuma amostra apresentou diferença significativa ao nivel de $5 \%$.

No caldo Melaço, as amostras D - J e D - I apresentaram diferença significativa ao nivel de $5 \%$ de acordo com o teste de Friedman. No $2^{\circ}$ grupo, as amostras que apresentaram diferença significativa foram $\mathrm{F}-\mathrm{B}, \mathrm{F}-\mathrm{B} ; \mathrm{F}-\mathrm{A}$ e $\mathrm{F}$ - E. No $3^{\circ}$ grupo, as amostras $\mathrm{K}-\mathrm{G}$ apresentaram diferença significativa ao nível de $5 \%$.

Os testes de escala foram realizados para possibilitar a comparação de todas as amostras, uma vez que nos testes de ordenação foram comparadas as amostras de um mesmo grupo. Para a realização dos testes de escala foram formados 6 grupos com as amostras avaliadas no teste de ordenação, completando, assim, o desenho experimental (Tabelas 4 e 5).
TABELA 4 - Formação dos 6 grupos de amostras cultivadas no caldo YEPD para realização do teste de escala

\begin{tabular}{cccccc}
\hline \multicolumn{7}{c}{ Grupos para o teste de escala no caldo YEPD } \\
\hline $1^{\circ}$ & $2^{\circ}$ & $3^{\circ}$ & $4^{\circ}$ & $5^{\circ}$ & $6^{\circ}$ \\
\hline C & C & H & H & H & H \\
A & H & D & F & F & K \\
H & D & F & K & K & J \\
& F & K & J & J & G \\
& K & J & B & G & I \\
\hline \multicolumn{7}{c}{ Amostras escolhidas } \\
\hline A & C & D & B \\
\hline
\end{tabular}

TABELA 5 - Formação dos 6 grupos de amostras cultivadas no Caldo Melaço para realização do teste de escala

\begin{tabular}{cccccc}
\hline \multicolumn{6}{c}{ Grupos para o teste de escala no caldo Melaço } \\
\hline $1^{\circ}$ & $2^{\circ}$ & $3^{\circ}$ & $4^{\circ}$ & $5^{\circ}$ & $6^{\circ}$ \\
\hline $\mathrm{D}$ & $\mathrm{D}$ & $\mathrm{K}$ & $\mathrm{K}$ & $\mathrm{K}$ & $\mathrm{K}$ \\
$\mathrm{F}$ & $\mathrm{K}$ & $\mathrm{C}$ & $\mathrm{B}$ & $\mathrm{H}$ & $\mathrm{H}$ \\
$\mathrm{K}$ & $\mathrm{C}$ & $\mathrm{B}$ & $\mathrm{H}$ & $\mathrm{J}$ & $\mathrm{J}$ \\
& $\mathrm{B}$ & $\mathrm{H}$ & $\mathrm{J}$ & $\mathrm{A}$ & $\mathrm{G}$ \\
& $\mathrm{H}$ & $\mathrm{J}$ & $\mathrm{A}$ & $\mathrm{G}$ & $\mathrm{I}$ \\
\hline \multicolumn{7}{c}{ Amostras escolhidas } \\
\hline $\mathrm{F}$ & $\mathrm{D}$ & $\mathrm{C}$ & $\mathrm{B}$ & $\mathrm{E}$ \\
\hline
\end{tabular}

No $1^{\circ}$ grupo entraram as amostras colocadas nos primeiros lugares dos testes de ordenação realizados para os cultivos em caldo YEPD (C, A e H) e para o cultivo realizado em caldo Melaço (D, F e K). Neste $1^{\circ}$ grupo as amostras A e F foram escolhidas em seus meios de cultura, respectivamente, e as demais passaram para o $2^{\mathrm{o}}$ grupo. Para a formação do $2^{\mathrm{o}}$ grupo entraram as amostras colocadas nos segundos lugares dos testes de ordenação realizados para os cultivos em caldo YEPD (D, F e K) e para o cultivo em caldo Melaço (C, B e H). A estas foram acrescentadas as amostras eliminadas do $1^{\circ}$ grupo do teste de escala, tanto para o caldo YEPD (C e H) como para o caldo Melaço (D e K). As amostras escolhidas foram a C no cultivo em caldo YEPD e a D no cultivo em caldo Melaço. O $3^{\circ}$ grupo foi composto pelas amostras eliminadas do $2^{\circ}$ grupo do teste de escala, que para o cultivo em caldo YEPD foram as amostras D, F, K e $\mathrm{H}$ e para o cultivo em caldo Melaço as amostras C, B, H e K. A estas se juntou a amostra J, tanto no caldo YEPD como no caldo Melaço, colocada em terceiro lugar nos testes de ordenação. Foram escolhidas neste grupo as amostras D, no caldo YEPD, e C, no caldo Melaço. O $4^{\circ}$ grupo foi composto pelas amostras eliminadas do $3^{\circ}$ grupo, que no caldo YEPD foram F, K, J, K e $\mathrm{H}$ e no caldo Melaço B, H, J e K. A elas se juntaram as amostras B, no caldo YEPD, e A, no caldo Melaço, oriundas do terceiro lugar nos testes de ordenação. A amostra escolhida foi a B, no caldo YEPD e no caldo Melaço. A amostra G, tanto no caldo YEPD como no caldo Melaço, colocada em terceiro lugar nos testes de ordenação formou o $5^{\underline{o}}$ grupo no teste de escala, junto com as eliminadas do $4^{\circ}$ grupo, que foram, no caldo YEPD, as amostras $\mathrm{F}, \mathrm{K}, \mathrm{J}$ e H, e no caldo Melaço, A, H, J e K. As amostras escolhidas foram F, no caldo YEPD, e A, no caldo Melaço.

$\mathrm{Na}$ formação destes 6 grupos para os testes de escala, todas as amostras foram sendo comparadas. As amos- 
tras escolhidas em cada grupo foram comparadas indiretamente com as demais, uma vez que, por serem escolhidas pela equipe de provadores, mostraram-se superiores no atributo que estava sendo julgado, não havendo necessidade de continuar participando das comparações com as demais. As amostras eliminadas em cada um dos grupos, por outro lado, continuaram a ser comparadas com as demais, quando passavam, sucessivamente, para os grupos posteriores. Deste fato, podemos afirmar que todas as amostras foram comparadas direta ou indiretamente.

Um teste de escala confirmativo foi realizado com as amostras escolhidas com o propósito de avaliar a competência da equipe de provadores em utilizar este desenho experimental. Este fato seria comprovado se, em um novo teste de escala, as amostras escolhidas permanecessem na mesma colocação resultante dos testes de escala anteriores. O resultado deste teste de escala confirmativo, onde as 6 amostras escolhidas obtiveram, mais uma vez, a classificação conseguida anteriormente, comprovou a aplicabilidade do desenho experimental e a habilidade de seu uso pela equipe de provadores treinada. É importante ressaltar que os resultados foram confirmados tanto para o cultivo em caldo YEPD como em caldo Melaço (Tabelas 6 e 7).

TABELA 6 - Amostras escolhidas nos testes de escala e no teste de escala confirmativo no caldo YEPD

\begin{tabular}{cccccc}
\hline \multicolumn{7}{c}{ Amostras escolhidas } \\
\hline $1^{\circ}$ grupo & $2^{\circ}$ grupo & $3^{\circ}$ grupo & $4^{\circ}$ grupo & $5^{\circ}$ grupo & $6^{\circ}$ grupo \\
\hline A & C & D & B & F & J \\
\hline \multicolumn{7}{c}{ Amostras escolhidas no teste confirmativo } \\
\hline $1^{\circ}$ lugar & $2^{\circ}$ lugar & $3^{\circ}$ lugar & $4^{\circ}$ lugar & $5^{\circ}$ lugar & $6^{\circ}$ lugar \\
\hline A & C & D & B & F & J \\
\hline
\end{tabular}

TABELA 7 - Amostras escolhidas nos testes de escala e no teste de escala confirmativo no caldo Melaço

\begin{tabular}{cccccc}
\hline \multicolumn{7}{c}{ Amostras escolhidas } \\
\hline $1^{\circ}$ grupo & $2^{\circ}$ grupo & $3^{\circ}$ grupo & $4^{\circ}$ grupo & $5^{\circ}$ grupo & $6^{\circ}$ grupo \\
\hline F & D & C & B & A & H \\
\hline \multicolumn{7}{c}{ Amostras escolhidas no teste confirmativo } \\
\hline $1^{\circ}$ lugar & $2^{\circ}$ lugar & $3^{\circ}$ lugar & $4^{\circ}$ lugar & $5^{\circ}$ lugar & $6^{\circ}$ lugar \\
\hline $\mathrm{F}$ & $\mathrm{D}$ & $\mathrm{C}$ & $\mathrm{B}$ & $\mathrm{A}$ & $\mathrm{H}$ \\
\hline
\end{tabular}

No tratamento estatístico, o $1^{\mathrm{o}}, 2^{\mathrm{o}}, 3^{\mathrm{o}}$ e $4^{\mathrm{o}}$ grupos e as amostras do teste de escala confirmativo, cultivadas no caldo YEPD e no caldo Melaço, apresentaram diferença significativa ao nivel de $5 \%$ na análise de variância (ANOVA). É interessante ressaltar que, as amostras do $5^{\circ}$ e $6^{\circ}$ grupos, tanto as cultivadas no caldo YEPD como no caldo Melaço, não apresentaram diferença significativa ao nivel de 5\% no tratamento estatístico. Podemos supor que isto ocorreu porque as amostras que apresentavam aroma frutal mais forte foram escolhidas logo nos primeiros testes de escala, ficando para os últimos grupos àquelas com aroma frutal mais fraco sendo, portanto, mais dificeis de serem diferenciadas sensorialmente.

No caldo YEPD, as médias do $1^{\circ}$ grupo não apresentaram diferença significativa ao nível de $5 \%$ no teste de Tukey. No $2^{\mathrm{o}}$ grupo as médias das amostras $\mathrm{C}$ e H apre- sentaram diferença significativa ao nível de $5 \%$. No $3^{\circ}$ grupo as médias das amostras que apresentaram diferença significativa ao nivel de 5\% foram: D e K; D e J; D e H; F e $\mathrm{K} ; \mathrm{F}$ e J. No $4^{\circ}$ grupo as médias que apresentaram diferença significativa ao nível de $5 \%$ foram as das amostras B e K; B e J; B e H; F e K; F e J; F e H; D e K; D e J; D e H; F e $\mathrm{K} ; \mathrm{F}$ e J. No $5^{\circ}$ e $6^{\circ}$ grupos as médias não apresentaram diferença significativa ao nível de $5 \%$. No teste de escala confirmativo as médias que apresentaram diferença significativa ao nivel de $5 \%$ foram as das amostras: A e F; A e $\mathrm{J} ; \mathrm{C}$ eJ; DeJ.

No caldo Melaço as médias das amostras do $1^{\circ}$ grupo não apresentaram diferença significativa ao nivel de 5\% no teste de Tukey. No 2 o grupo as médias que apresentaram diferença significativa ao nivel de $5 \%$ foram as das amostras: C e D; B e D; H e D. No $3^{\circ}$ grupo as médias que apresentaram diferença significativa ao nivel de $5 \%$ foram as das amostras $\mathrm{C}$ e H; C e J; C e K. No $4^{\circ}$ grupo as amostras que apresentaram suas médias com diferença significativa ao nível de 5\% foram: B e J; B e K. No 5o e $6^{\circ}$ grupos as médias não apresentaram diferença significativa ao nivel de $5 \%$. No teste de escala confirmativo as amostras que apresentaram média com diferença significativa ao nivel de 5\% foram: F e B; F e A; F e H; D e B; D e A; D e H; C e H.

Embora o método de blocos incompletos [9] seja bastante utilizado para a comparação de 6 amostras, uma limitação deste desenho experimental parece ser a necessidade de aumentar o número de provadores da equipe treinada, quando o número de amostras a ser avaliado obriga a organização de mais blocos do que o número de provadores que se tem na equipe. Conforme descrito pelos autores, um provador avalia apenas um bloco formado. Utilizando este desenho experimental, ao final do teste, cada amostra apresentará um total de 10 julgamentos e, segundo os autores, todas as amostras terão sido comparadas entre si. Embora esta comparação aconteça, parece uma desvantagem, do ponto de vista da confiabilidade ou da reprodutibilidade dos resultados, que o número total de julgamentos para cada amostra seja menor que o número de provadores. A equipe de provadores tem por finalidade totalizar o maior número de julgamentos possiveis para uma amostra, de modo a formar um consenso, onde os erros inerentes ao julgamento possam ser irrelevantes.

No desenho experimental sugerido neste trabalho, uma equipe de 11 provadores treinados julgou todas as 11 amostras, totalizando 8 sessões de avaliação. O número de provadores não variou em função do número de amostras. Isto vem a ser uma vantagem pelo fato de não haver necessidade de captar e treinar novos provadores, de acordo com o número de sessões a serem realizados. Além disso, no teste de escala do $6^{\circ}$ grupo foi obtida a classificação final das 11 amostras, onde 6 delas foram escolhidas como produtoras de aroma frutal mais forte e as demais foram classificadas em ordem decrescente de in- 
tensidade de aroma frutal, sem que houvesse necessidade de realizar mais testes comparativos.

O tratamento estatístico validou o desenho experimental proposto, mostrando que as amostras escolhidas, ou seja, aquelas que produziram aroma frutal mais forte, apresentaram diferença significativa ao nivel de $5 \%$, enquanto as demais não apresentaram esta diferença.

\section{4 - CONCLUSÕES}

De acordo com objetivos traçados neste trabalho e com os resultados obtidos podemos concluir que:

- as linhagens cultivadas no caldo YEPD e no caldo Melaço produziram aroma frutal suficiente para ser percebido pelos provadores nos testes comparativos. Desta forma, o desenho experimental pôde ser testado com as amostras cultivadas nestes meios de cultura;

- as amostras escolhidas em cada grupo foram comparadas indiretamente com as demais, uma vez que, por serem escolhidas pela equipe de provadores, mostraram-se superiores no atributo que estava sendo julgado, não havendo necessidade de continuar participando das comparações com as demais. As amostras eliminadas em cada um dos grupos, por outro lado, continuaram a ser comparadas com as demais, quando passavam, sucessivamente, para os grupos posteriores. Deste fato, podemos afirmar que todas as amostras foram comparadas direta ou indiretamente;

- $\quad$ o resultado do teste de escala confirmativo, onde as 6 amostras escolhidas obtiveram mais uma vez a classificação conseguida anteriormente, comprovou a aplicabilidade do desenho experimental e a habilidade de seu uso pela equipe de provadores treinada, sem que causasse fadiga nestes provadores. É interessante ressaltar que, os resultados foram confirmados tanto para o cultivo em caldo YEPD como em caldo Melaço;

- o desenho experimental proposto para testes sensoriais comparativos com um número superior a 6 amostras foi validado pelo tratamento estatístico, onde as amostras escolhidas, tanto no caldo YEPD como no caldo Melaço, apresentaram diferença significativa ao nivel de $5 \%$;

- esse desenho experimental pode ser aplicado à análise sensorial quando um grande número de amostras precisa ser comparado com equipes treinadas.

\section{5 - REFERÊNCIAS BIBLIOGRÁFICAS}

[1] AMERICAN TYPE CULTURE COLLECTION. Catalogue of Yeasts, $18^{\text {th }}$ ed.. Rockville: ATCC, 1990.

[2] BALL, R.D. Incomplete block designs for the minimisation of order and carry-out effects in sensory analysis. Food Quality and Preference, v. 8, n. 2, p. 111-118, 1997.
[3] DELAQUIS, P.; CLIFF, M.; KING, M.; GIRARD, B.; HALL, J.; REYNOLDS, A. Effect of two commercial malolactic cultures on the chemical and sensory properties of chancellor wines vinified with different yeasts and fermentation-temperatures. American Journal of Enology and Viticulture, v. 51, n. 1, p. 42-48, 2000.

[4] ETSCHMANN, M.M.W.; SELL, D.; SCHRADER, J. Screening of yeasts for the production of the aroma compound 2-phenylethanol in a molasses-based medium. Biotechnology Letters, v. 25, n. 7, p. 531-536, 2003.

[5] GABORIT, P.; MENARD, A.; MORGAN, F. Impact of ripening strains on the typical flavour of goat cheeses. International Dairy Journal, v. 11, n. 4-7, p. 315-325, 2001.

[6] HERNANDEZ, G.G.; DE LA TORRE, A.H.; LEON, J.J.A. Sensory analysis of traditionally produced red wine from the Taraconte-Acentejo area of the Canary Islands. Italian Journal of Food Science, v. 14, n. 1, p. 35-44, 2002.

[7] MAJDAK, A.; HERJAVEC, S.; ORLIC, S.; REDZEPOVIC, S.; MIROSEVIC, N. Comparison of wine aroma compounds produced by Saccharomyces paradoxus and Saccharomyces cerevisae strains. Food Technology and Biotechnology, v. 40, n. 2, p. 103-108, 2002.

[8] MARTIN, N.; BERGER, C.; SPINNLER, H.E. Sensory and instrumental flavor analyses of cheese curd cocultured with selected yeast and bacteria. Journal of Sensory Studies, v. 17, n. 1, p. 1-17, 2002.

[9] MEILGaARD, M.; CIVILlE, C.V.; CARR, B.T. Sensory Evaluation Techniques, $2^{a}$ ed.. New York: CRC Press, 1991.129p.

[10] PIGOTT, J.R. Design questions in sensory and consumer science. Food Quality and Preference, v. 6, n. 4, p. 217 220, 1995.

[11] REYNOLDS, A.G.; EDWARDS, C.G.; CLIFF, M.A.; THORNGATE, J.H.; MARR, J.C. Evaluation of yeast strains during fermentation of Riesling and Chenin blanc musts. American. Journal of Enology and Viticulture, v. 52, n. 4, p. 336-344, 2001.

[12] VAN DEN BREMT, K.; DELVAUX, F.R.; VERACHTERT, H.; DERDELINCKX, G. Biogeneration of flavors: Performance of Candida methanolovescens strains in nonalcoholic-beer. Journal of the American Society of Brewing Chemists, v. 59, n. 2, p. 80-83, 2001.

[13] WATANABE, M.; FUKUDA, K.; ASANO, K.; OHTA, S. Mutants of bakersyeasts producing a large amount of isobutyl alcohol or isoamyl alcohol, flavour components of bread. Applied Microbiology and Bacteriology, v. 34, n. 2, p. 154-159, 1990.

\section{6 - AGRADECIMENTOS}

Os autores agradecem a Gildo Almeida da Silva, do Centro Nacional de Pesquisa da Uva e do Vinho EMBRAPA pela doação das culturas de leveduras. Agradecem também a Cláudia Cunha, Fábio Azamor, Felipe Jung, Flávia Duta, Luciene Neves, Maria Helena Leão, Narcisa Furtado, Paula Salles, Priscila Fernanda, Priscila Finotelli, Valéria Souza e Waldemar de Souza pelos seus julgamentos como provadores. 